\title{
Vectorcardiographic Diagnosis of Combined Ventricular Hypertrophy in Adult Patients
}

\author{
Tadayuki HIRoki, M.D.*
}

\begin{abstract}
SUMMARY
The vectorcardiograms of 60 adult patients with established CVH mainly due to acquired heart diseases were analyzed. The study showed that there were essentially 3 characteristic QRS loop patterns for $\mathrm{CVH}$. In approximately one-fourth of the whole patients, a diagnosis of $\mathrm{CVH}$ could be made on the proposed vectorcardiographic criteria. It was found that the vectorcardiographic criteria of CVH in infants and children with ventricular septal defect and patent ductus arteriosus were also applicable to that of adult patients with CVH due to a variety of heart diseases provided some modifications of the vectorcardiographic criteria were made.
\end{abstract}

\section{Additional Indexing Words:}

Acquired heart diseases Frank lead system VCG classification QRS loop analysis

T $\mathrm{T}$ is generally agreed that the diagnosis of combined ventricular hypertrophy by the conventional electrocardiogram is difficult or sometimes even impossible. ${ }^{1-6)}$ Reports on vectorcardiographic studies of combined ventricular hypertrophy (CVH) have been limited except in infants and children with congenital heart disease. ${ }^{7-9}$ ) The purpose of this study is to analyze the vectorcardiographic findings in adult patients with acquired heart disease who have definite anatomical or hemodynamic evidence of combined ventricular hypertrophy and to determine whether the vectorcardiogram may improve the diagnostic accuracy of the scalar electrocardiogram.

\section{Metirods and Materials}

Sixty cases from the Cincinnati General Hospital with definite hemodynamic or anatomical abnormalities to suggest CVH were included in this study. The

From the Cardiac Laboratory, Department of Medicine, University of Cincinnati College of Medicine, and the Cincinnati General Hospital, Cincinnati, Ohio, U.S.A.

* Research Fellow Supported by the Mabel S. Stonehill Fund for Electrocardiographic Research, University of Cincinnati.

Reprint requests: Tadayuki Hiroki, M.D., Electrocardiographic and Vectorcardiographic Laboratory, Department of Medicine, Fukuoka University Hospital, Nanakuma, Nishiku, Fukuoka, Japan,

Received for publication December 29, 1973. 
hemodynamic evidence to suggest left ventricular hypertrophy (LVH) included an elevation of the left ventricular systolic pressure to greater than $160 \mathrm{mmHg}$ or the left ventricular end-diastolic pressure to greater than $13 \mathrm{mmHg}$. Right ventricular hypertrophy (RVH) was considered to be present if there is an elevation of the right ventricular systolic pressure to greater than $32 \mathrm{mmHg}$ or the right ventricular end-diastolic pressure to greater than $6 \mathrm{mmHg}$. The anatomical criteria for $\mathrm{CVH}$ required a left ventricular free wall thickness of more than $13 \mathrm{~mm}$ and right ventricular free wall thickness of more than $3 \mathrm{~mm}$. Of 60 cases of $\mathrm{CVH} 22$ cases were based on anatomical evidence and 38 cases were based on hemodynamic evidence. Thirty-four patients had valvular disease such as mitral stenosis with aortic insufficiency or mitral insufficiency. Ten patients had primary myocardial disease, 6 had hypertensive heart disease, and 3 had congenital heart disease such as ventricular septal defect or patent ductus arteriosus. The mean age of the entire group was 45.4 years. The age and sex distribution is shown in Table I.

Table I. Age and Sex Distribution of 60 Patients with CVH

\begin{tabular}{c|cc:c}
\hline Group (years) & Male & Female & Total \\
\hline $21-30$ & 7 & 3 & 10 \\
$31-40$ & 6 & 7 & 13 \\
$41-50$ & 10 & 8 & 18 \\
$51-60$ & 6 & 2 & 8 \\
Greater than 60 & 8 & 3 & 11 \\
Total & 37 & 23 & 60
\end{tabular}

Mean age: 45.4 years.

To examine the relationship between the clinical findings and the vectorcardiographic features the cases were divided into left and right ventricular groups. The left ventricular preponderant group consisted of cases in which RVH developed because of left ventricular failure ( $\mathrm{LV}$ group). The right ventricular preponderant group included cases in which RVH was not the secondary result of LVH disease (RV group).

Conditions which excluded cases from the present study were electrocardiographic signs or anatomic evidence of myocardial infarction and electrocardiographic evidence of complete left or right bundle branch block.

The vectorcardiograms were recorded with the Frank lead system. The subjects were supine and the chest electrodes were placed at the level of the fifth intercostal space at the sternal margin. The reference frame for angular notation is shown in Fig. 1. In the present study the QRS and T loops in the frontal and transverse planes were analysed. The following measurements of the QRS loop were obtained: (1) configuration of the QRS loop, (2) magnitude and direction of the maximum QRS vector, (3) direction of inscription of the QRS loop, (4) duration of the QRS loop, (5) magnitude of the maximum leftward and the maximum rightward QRS force as projected on the $\mathrm{X}$ axis and their ratio, (6) maximum posterior and maximum anterior $Q R S$ forces as projected on the $Z$ axis and their ratio, ( 7 ) area quadrant distribution cxpressed as the percentage of total area, (8) maximum left anterior QRS force, (9) maximum left posterior QRS force, (10) maximum 


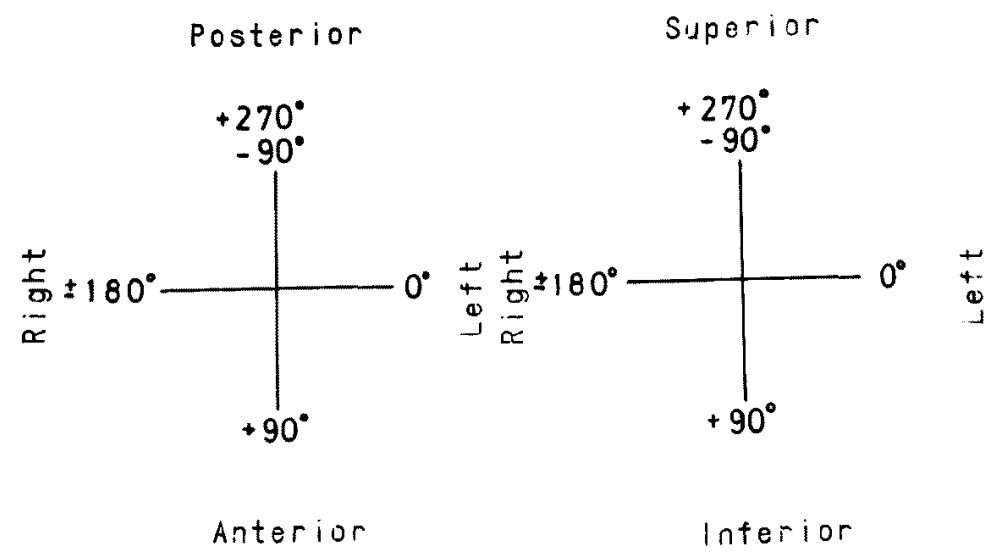

Fig. 1. Reference frame for angular notation in both transverse and frontal planes.

right posterior QRS force, (11) maximum right anterior QRS force, (12) ratio of these forces, (13) magnitude and direction of initial $0.02,0.04 \mathrm{sec}$ vector, (14) magnitude and direction of terminal 0.02, $0.04 \mathrm{sec}$ vector, (15) direction of the initial deflection and (16) direction of the terminal deflection. The method of determination of the last 2 parameters has been described previously. ${ }^{12}$ The maximum right posterior, right anterior, left posterior and left anterior QRS forces were defined as the magnitude from the $O$ point to the most far distant point on the loop in each quadrant. The $\mathrm{T}$ loops were analysed only for magnitude and direction of the maximum $T$ vector and direction of inscription of the loop.

\section{REsults}

Following the evaluation of the vectorcardiograms, it was apparent that the QRS loop patterns fell into 6 main groups, namely of groups of $\mathrm{CVH}$, left ventricular hypertrophy $(\mathrm{LVH})$, right ventricular hypertrophy $(\mathrm{RVH})$, incomplete left bundle branch block (incomplete LBBB), incomplete right bundle branch block (incomplete RBBB), and nonspecific QRS loop shown in Figs. 2, 3, and 4. The diagnosis of CVH was made if some of the following vectorcardiographic features for both $\mathrm{LVH}$ and $\mathrm{RVH}$ were fulfilled. The group of CVH was subdivided into 3 main types. Type A CVH is characterized by large anterior as well as large posterior QRS forces. Type B CVH revealed large right posterior as well as left posterior forces in the transverse 


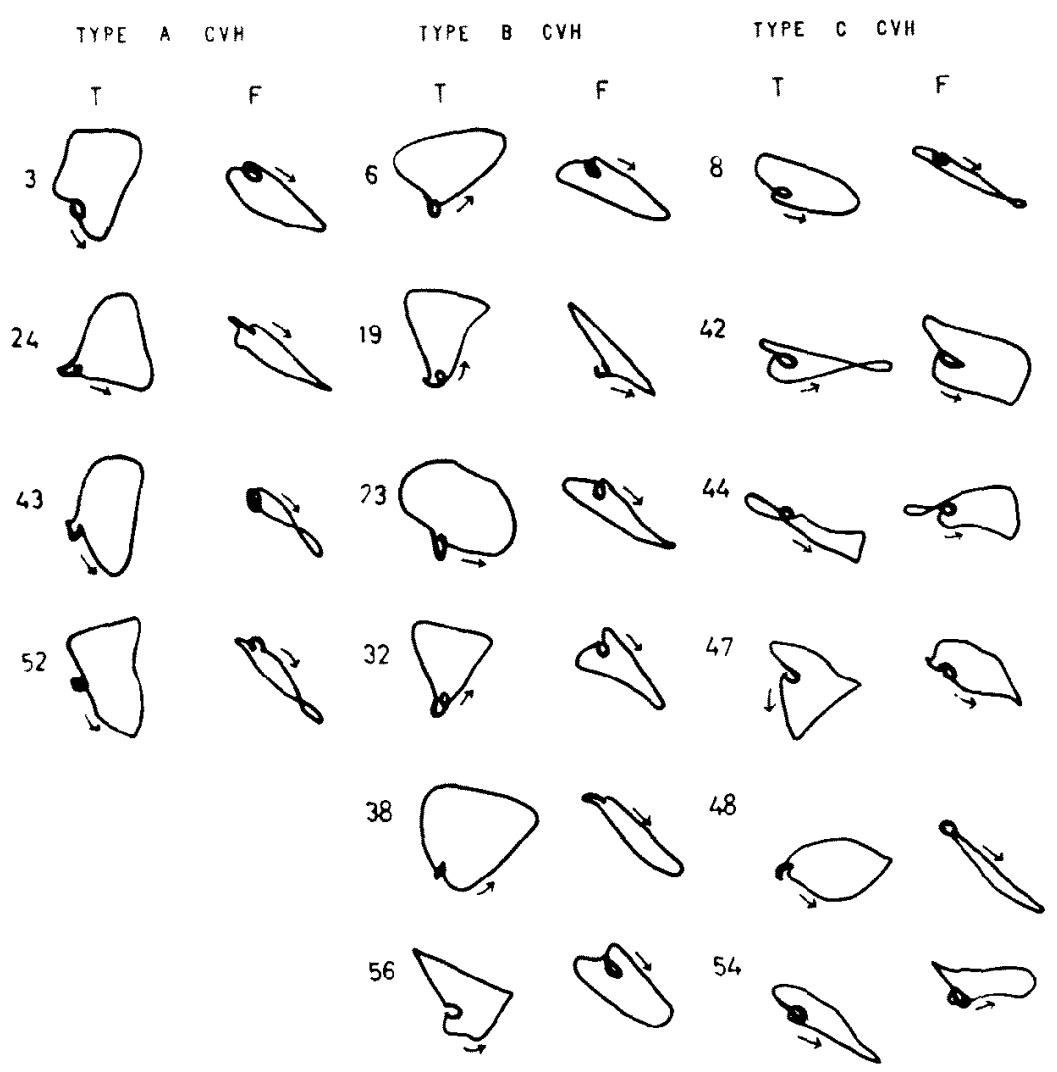

Fig. 2. QRS and $\mathrm{T}$ vector loops of 16 cases diagnosing $\mathrm{CVH}$.

QRS loop. In type C CVH the transverse QRS loop was anteriorly oriented and the frontal QRS loop was displaced leftward superiorly and inscribed counterclockwise or the magnitude of the maximum QRS vector was increased and exceeded normal range. These patterns were found in 16 cases $(26.7 \%)$. The quantitative features of the QRS and T loops for CVH are set out in Table II. The mean magnitude of the major QRS force directing to the left and posteriorly in the transverse plane was $1.6 \mathrm{mV}$ for type A CVH and $1.7 \mathrm{mV}$ for type $\mathrm{B} \mathrm{CVH}$. The mean magnitude of both the left anterior QRS force in type A CVH and the right posterior QRS force in type B CVH was $1.0 \mathrm{mV}$ and $1.4 \mathrm{mV}$ respectively. Only 4 patients with the $\mathrm{CVH}$ patterns had a maximum $\mathrm{QRS}$ vecter above $2.0 \mathrm{mV}$ in the frontal plane and 3 patients in the transverse plane. The mean maximum $\mathrm{QRS}$ vector in type $\mathrm{A}$ of $\mathrm{CVH}$ was $1.7 \mathrm{mV}$ in the frontal plane and $1.6 \mathrm{mV}$ in the transverse plane. The significant finding in the arca quadrant distribution was found in type $\mathrm{C} \mathrm{CVH}$, where the mean left anterior area was $60.3 \%$ of the wholc QRS loop arca in the transverse plane, and in type B CVH the right posterior area was above 

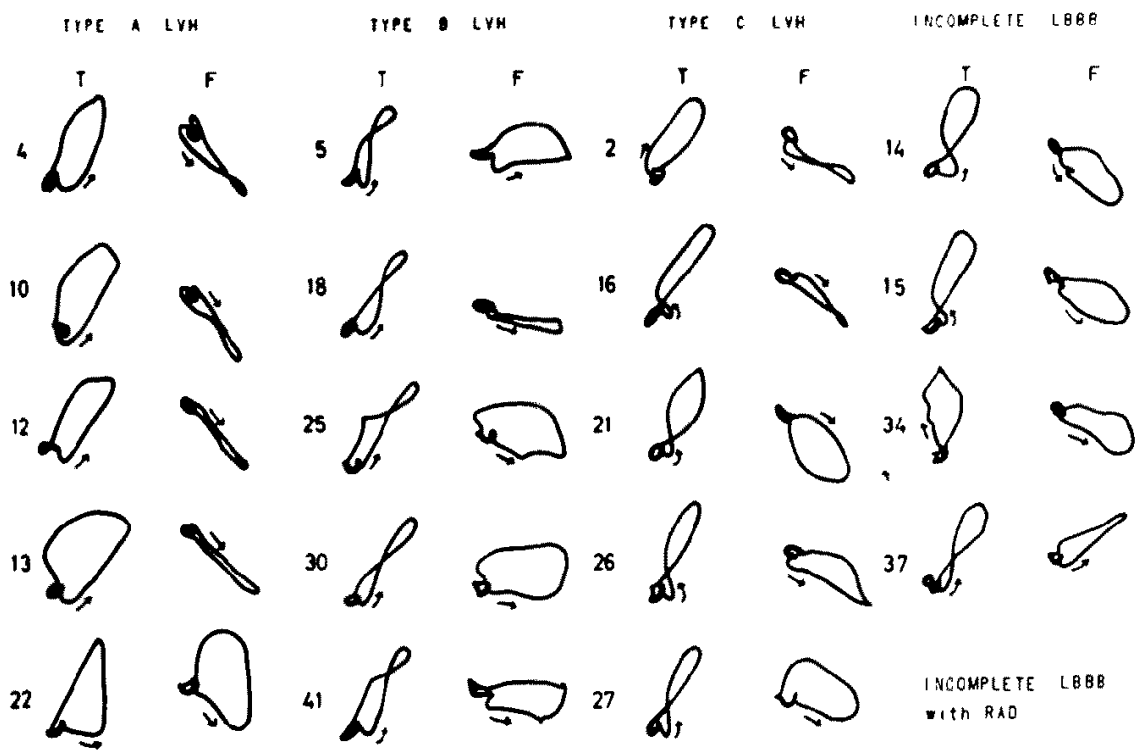

33
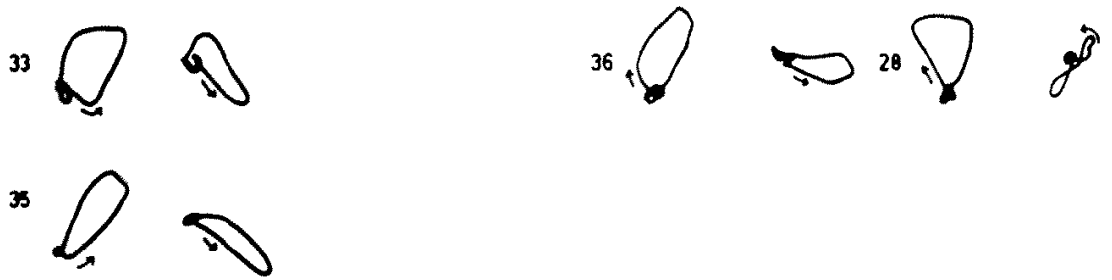

Fig. 3. QRS and $\mathrm{T}$ vector loops of 18 and 5 cases diagnosing $\mathrm{LVH}$ and incomplete $\angle B B B$ respectively.

$20 \%$ of the whole QRS loop area in 4 of 6 cases. The terminal deflection in the transverse QRS loop was displaced far posteriorly and to the right and was most prominent in type B CVH, where the mean direction of the terminal deflection was minus 11.7 degrees and the magnitude of the right posterior forces $1.4 \mathrm{mV}$ in average. The direction of the initial deflection varied widcly thus rendering this parameters of little importance. The duration of the QRS loop in CVH cases was slightly increased compared with that of the normal adult population. As for the direction of inscription of the QRS loop 14 cases with CVH showed a counterclockwise transverse QRS loop and 2 cases of type $\mathrm{C}$ CVH showed a figure-of-eight configuration. The direction of inscription of the frontal QRS loop was clockwise in 7 cases, counterclockwise in 1 and a figure-of-eight configuration in 2. However, the initial portion of the QRS loop of types A and B CVH it was inscribed clockwise with one exception contrasting with the leftward posteriorly oriented maximum QRS vector in the transverse plane. The frontal QRS loop of type C CVH showed 


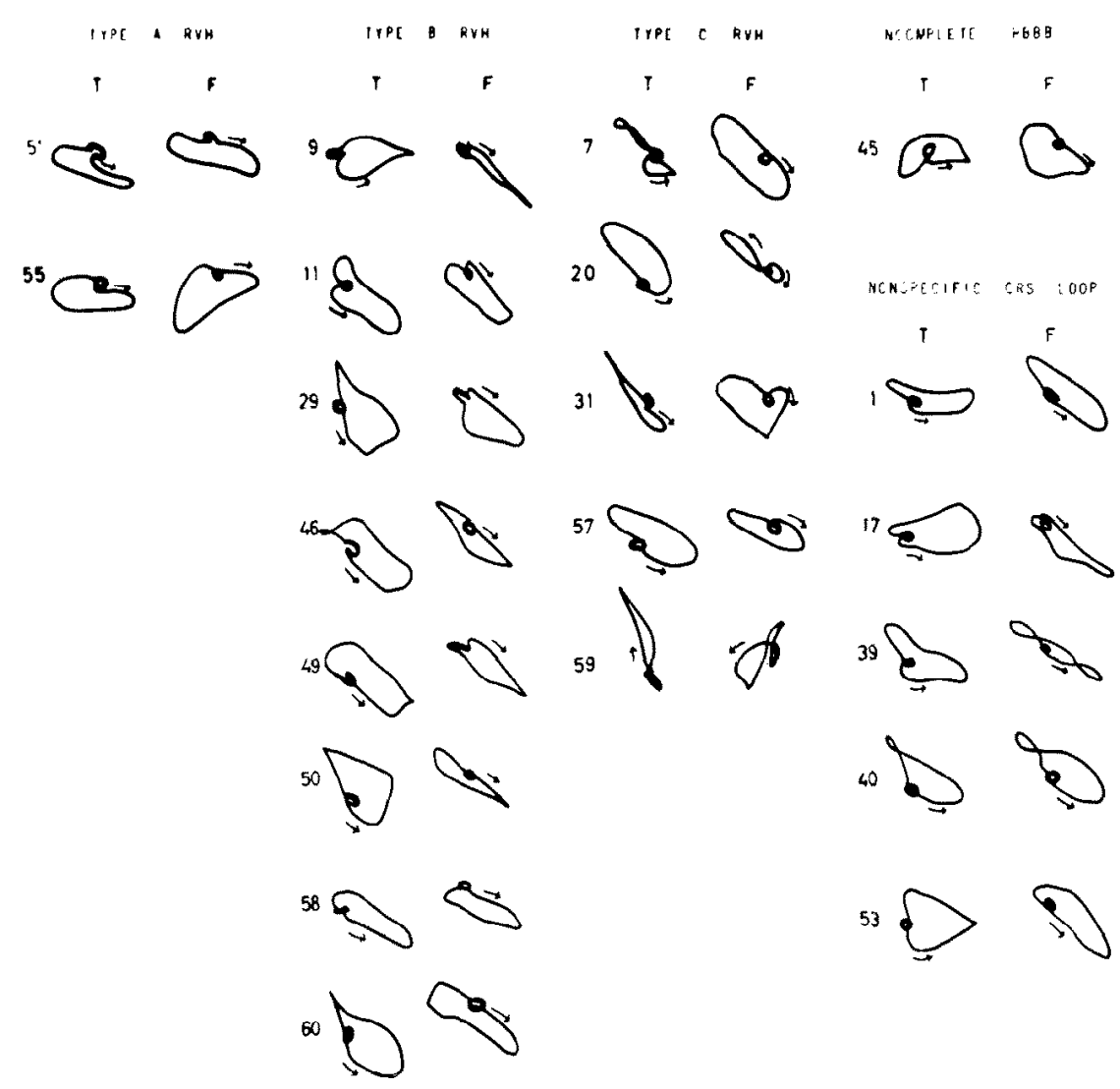

Fig. 4. QRS and $T$ vector loops of 15,1 and 5 cases diagnosing $\mathrm{RVH}$, incomplete RBBB and nonsepcific QRS loop respectively.

counterclockwise inscription in 4 cases and it was displaced to 10 degrees or above in average. The $\mathrm{T}$ loop in CVH cases showed various kinds of configuration. The magnitude of the maximum $\mathrm{T}$ vector was almost within normal limits. The mean values of the maximum $T$ vector in all types of CVH were around $0.35 \mathrm{mV}$ in both transverse and frontal planes. However, the direction of the maximum $T$ vector showed a wide scatter in each type of CVH rendering this parameter of little importance.

Eighteen cases displayed a LVH pattern in which the magnitude of the maximum QRS vector was increased to $2.2 \mathrm{mV}$ or more in the transverse plane or to $2.0 \mathrm{mV}$ or more in the frontal plane. The maximum QRS vector was directed to the left and posteriorly. The group of LVH was subdivided into 2 types tentatively on basis of the direction of inscription of the transverse QRS loop. Type A LVH showed a counterclockwise QRS loop in the transverse plane, and type B LVH showed a figure-of-eight configuration with 
Table II. Main Vectorcardiographic Features of CVH Group

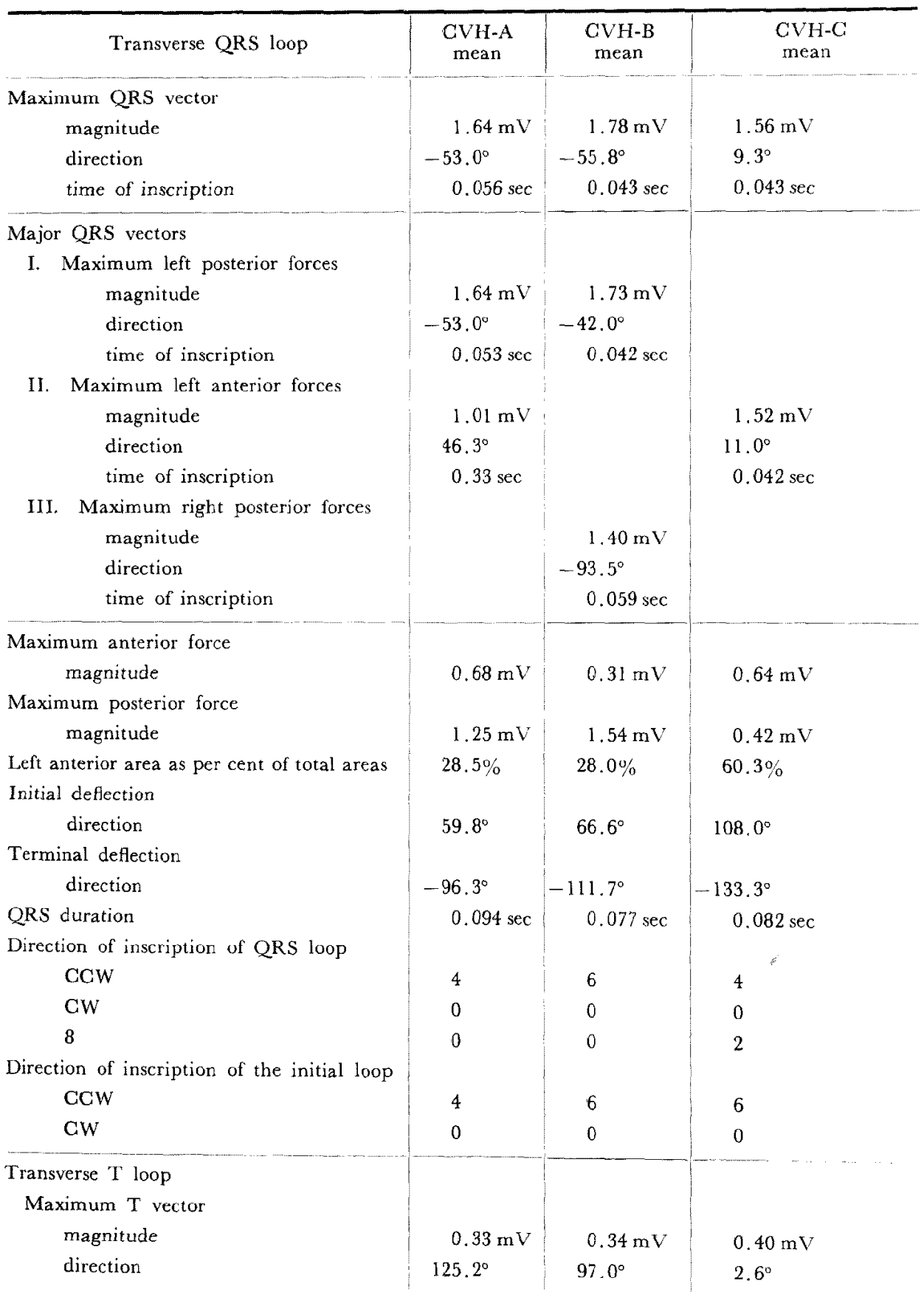

Continued... 
Table II. Continued

\begin{tabular}{|c|c|c|c|}
\hline Transverse QRS loop & $\begin{array}{l}\mathrm{CVH}-\mathrm{A} \\
\text { mean }\end{array}$ & $\underset{\text { mean }}{\mathrm{CVH}-\mathrm{B}}$ & $\underset{\text { mean }}{\text { CVH-C }}$ \\
\hline \multicolumn{4}{|l|}{ Frontal QRS loop } \\
\hline \multicolumn{4}{|l|}{ Maximum QRS vector } \\
\hline magnitude & $1.78 \mathrm{mV}$ & $1.96 \mathrm{mV}$ & $2.0 \mathrm{mV}(\mathrm{CW}$ group $)$ \\
\hline direction & $41.0^{\circ}$ & $69.6^{\circ}$ & $\begin{array}{l}1.72(\mathrm{CCW} \text { group) } \\
40.5^{\circ}(\mathrm{CW}) \\
9.7^{\circ}(\mathrm{CCW})\end{array}$ \\
\hline time of inscription & $0.53 \mathrm{sec}$ & $0.042 \mathrm{sec}$ & $0.043 \mathrm{sec}$ \\
\hline \multicolumn{4}{|c|}{ Direction of inscription of QRS loop } \\
\hline CCW & 0 & 1 & 4 \\
\hline CW & 2 & 5 & 0 \\
\hline 8 & 2 & 0 & 2 \\
\hline \multicolumn{4}{|c|}{ Direction of inscription of the initial loop } \\
\hline CGW & 0 & 1 & 4 \\
\hline CW & 4 & 5 & 2 \\
\hline \multicolumn{4}{|l|}{ Frontal $\mathrm{T}$ loop } \\
\hline \multicolumn{4}{|l|}{ Maximum $T$ vector } \\
\hline magnitude & $0.30 \mathrm{mV}$ & $0.32 \mathrm{mV}$ & $0.39 \mathrm{mV}$ \\
\hline direction & $83.3^{\circ}$ & $91,0^{\circ}$ & $71.0^{\circ}$ \\
\hline
\end{tabular}

counterclockwise inscription of the proximal portion and clockwise inscription of the distal portion. The possibility of coexistence of incomplete LBBB could not be ruled out in the latter type. Incomplete LBBB pattern in which the transverse QRS loop showed a figure-of-eight or clockwise inscription but the magnitude of the maximum QRS vector directing to the left and posteriorly was less than $2.0 \mathrm{mV}$ was found in 5 cases.

The group of RVH was found in 15 cases. There were 3 types of QRS loop representing $\mathrm{RVH}$ which was diagnosed on basis of the following features, namely (1) the transverse QRS loop was displaced anteriorly and rightward so that most of the loop was located in the right anterior quadrant and the direction of inscription of the QRS loop was clockwise (type A RVH), (2) the transverse QRS loop showed forward displacement and one-hall or more of the QRS area was located anteriorly and the direction of inscription of the loop was countcrclockwise (type B RVH), (3) the transverse QRS loop showed posterior and rightward displacement so that $20 \%$ or more of the loop area was located in the right posterior quadrant and the direction of inscription of the loop was clockwise or the loop showed a figure-of-eight pattern (type $\mathrm{C}$ RVH). The types A, B, C RVH were found in 2, 8, and 5 cases respectively. Incomplete RBBB pattern in which the QRS loop was similar to those of complete RBBB but the QRS duration was less than $0.12 \mathrm{sec}$ was observed in only 
Table III. The Number of Cases Diagnosed as CVH, LVH, Incomplete

LBBB, Incomplete RBBB, and Nonspecific QRS Loop in Relation to Right Ventricular Predominant Cases (RV Group) and Left

Ventricular Predominant Cases (LV Group) of CVH

\begin{tabular}{|c|c|c|c|c|c|c|}
\hline $\begin{array}{l}\text { Classification Due } \\
\text { to Hemodynamic or } \\
\text { Anatomic Findings }\end{array}$ & CVH & LVH & RVH & $\begin{array}{l}\text { Incom- } \\
\text { plete } \\
\text { LBBB }\end{array}$ & $\begin{array}{l}\text { Incom- } \\
\text { plete } \\
\text { RBBB }\end{array}$ & $\begin{array}{l}\text { Nonspecific } \\
\text { QRS Loop }\end{array}$ \\
\hline RV Group & $7(11.7 \%)$ & 0 & $14(23.3 \%)$ & 0 & 0 & 0 \\
\hline LV Group & $9(15.0 \%)$ & $18(30.0 \%)$ & $1(1.7 \%)$ & $5(8.3 \%)$ & $1(1.7 \%)$ & $5(8.3 \%)$ \\
\hline Total & $16(26.7 \%)$ & $18(30.0 \%)$ & $15(25.0 \%)$ & $5(7.8 \%)$ & $1(1.7 \%)$ & $5(8.3 \%)$ \\
\hline
\end{tabular}

1 patient. Other nonspecific QRS loop pattern was present in 5 patients or $8 \%$ of the entire series.

Among the 60 cases studied 18 and 5 cases manifested exclusively LVH and incomplete LBBB respectively. These patterns were observed mostly in patients with aortic valvular disease showing left ventricular preponderance in either hemodynamic or anatomic finding. The pattern which manifested exclusively RVH was observed in 15 cases. They were observed mostly in patients with either mitral valvular disease or primary myocardial disease demonstrating right ventricular preponderance. Five cases manifested nonspecific QRS loop were observed in patients with either mitral valvular disease, aortic valvular disease or hypertensive heart disease. The CVH pattern was seen mostly in patients with combined valvular disease with mitral stenosis. Only 3 patients with aortic valvular disease showed the $\mathrm{CVH}$ pattern of vectorcardiogram. Two cases with ventricular septal defect showed the type $\mathrm{C}$ CVH pattern. Approximately three-fourth of thc CVH cases manifested right ventricular preponderance.

\section{Discussion}

The diagnosis of CVH can be made if the characteristics of both right and left ventricular hypertrophy arc manifested separately in the QRS loops. In the present series there are essentially 3 vectorcardiographic patterns that we believe represent $\mathrm{CVH}$. They have been designated as types $\mathrm{A}, \mathrm{B}$, and $\mathrm{C}$. Type A CVH showing prominent initial anterior forces as well as large late posterior forces in the transverse QRS loop corresponds to the so-called pic plate pattern of the QRS loop ${ }^{9)}$ or the Katz-Wachtel signs' ${ }^{2)}$ in the electrocardiogram which have been described in the infants and children with ventricular septal defect or patent ductus arteriosus. In type A CVH the initial large anterior QRS forces could be attributed to right ventricular 
hypertrophy and prominent posterior leftward QRS forces to the hypertrophied left ventriclc. Typc B CVH is similar to the posterior counterclockwise transverse QRS loop reported by Varriale and associates. ${ }^{13)}$ In type B CVH the late right posterior QRS forces could be attributed to the hypertrophy of the region of outflow tract of the basal portion of the right ventricle. ${ }^{14}$ ) Type $\mathrm{C}$ CVH is characterized by the coexistence of an anteriorly oriented transverse QRS loop and a frontal QRS loop which is displaced leftward superiorly and inscribed counterclockwise or the increased magnitude of the frontal maximum QRS vector. In this type the large anterior QRS forces in the transverse plane could be attributed to the hypertrophied right ventricle and the abnormal QRS forces in the frontal plane to the left ventricle.

Chou and Helm have proposed 3 vectorcardiographic patterns for $\mathrm{CVH}$ in adults based on clinical evidence. ${ }^{15)}$ The qualitative features of types $\mathrm{A}$ and $\mathrm{B}$ CVH in the present series were almost same as those of Chou and Helm, however the remaining type of CVH in which the transverse QRS loop was displaced anteriorly and inscribed clockwise to suggest RVH, whereas the frontal QRS loop inscribed counterclockwise was not found in the present study.

Type $\mathrm{C}$ CVH in our adult series shows similar frontal QRS loop as described by Beregovich and associates ${ }^{7)}$ and Dack ${ }^{8}$ in infants and children, however the direction of inscription of the transverse QRS loop differs. Such a discrepancy with our study may be explained by the different varieties of disease studied, the different age of the patient as well as the different lead systems used. In support of the view that additional criteria of CVH other than those observed by Dack and Beregovich and associates may occur in the adults, we believe that the above mentioned type G QRS loop pattern is indicative of $\mathrm{CVH}$ in the adults, provided that the superior deviation of the frontal maximum QRS vector associated with myocardial fibrosis can be ruled out. Accordingly the diagnosis of CVH from such vectorcardiographic pattern described as type $\mathrm{C}$ CVH should be made with less certainty than that of types $\mathrm{A}$ and $\mathrm{B}$ CVH.

A large initial segment of the transverse QRS loop directing to the right and anteriorly in presence of the latc leftward posterior forces which was described by Beregovich and associations as one of the basic patterns for GVH was not observed in the present adult series. However, relative physiologic right ventricular preponderance may be still sustained in the infants and children although it has subsided in the adults. Therefore, it would seem reasonable that CVH pattern would not exhibit the same electrical manifestation in the adult group as would be observed in the infants and children with similar hypertrophy. 
It may therefore be concluded from the results of our study that a diagnosis of CVH in the adults with acquircd heart disease can be made on the basis of the above mentioned distinctive vectorcardiographic features, some of which are compatible with the previously established vectorcardiographic criteria of CVH in the infants and children with ventricular septal defect and patent ductus arteriosus.

The present series revealed a sensitivity of approximately $25 \%$ in the vectorcardiographic correct diagnosis of $\mathrm{CVH}$ in 60 proven cases. One of the reasons for such a low sensitivity may be attributed to that most cases with $\mathrm{CVH}$ tend to manifest either $\mathrm{LVH}$ or $\mathrm{RVH}^{11}$ ) only. Another reason is that a proportionate increase of both the right and left ventricles results in a cancellation or counterbalance of opposed vectorial forces resulting in a nonspecific QRS loop in cases with established CVH. ${ }^{10}$ However, the sensitivity still compares favorably with that obtained with the conventional electrocardiograph. ${ }^{6)}$

Langendorf pointed out that CVH could be diagnosed by electrocardiographic signs of LVH with right axis deviation of the mean QRS axis exceeding 90 degrees. $^{1)}$ However, the direction of the maximum QRS vector in the frontal plane which corresponds to the mean QRS axis in the electrocardiogram was less than 90 degrees in all of our cases. From this it would be indicated that the vertical heart position less than 90 degrees associated with LVH can not exclude the possibility of GVH. This might be one of the contributing factors related to the low recognition rate of $\mathrm{CVH}$ by electrocardiogram.

Recently, Varriale and associates reported that the posterior counterclockwise QRS loop in the transverse plane which corresponds to type B CVH in the present series was found in two-thirds of the patients in the adult patients with GVH. ${ }^{13)}$ However, this type of CVH in our study was found only in one-tenth of the patients. This discrepancy may be due to the different severity of the lesion or varied representatives of the overall population of CVH. It also may be due to the different estimation of the vectorcardiographic criteria employed in which the mean magnitude of the left posterior forces and right posterior forces in the transverse QRS loop was $0.96 \mathrm{mV}, 0.68 \mathrm{mV}$ in their cases and $1.7 \mathrm{mV}, 1.4 \mathrm{mV}$ in our cases respectively. On the other hand neither type A nor C QRS loop pattern seen in the present series was found in their series except for 1 case which was described as a large biphasic anterior and posterior loop pattern in the transverse plane which was precluded from their CVH analysis. However, that pattern in Varriale's case was similar to that of type A CVH in the present series which was observed in 4 cases. 


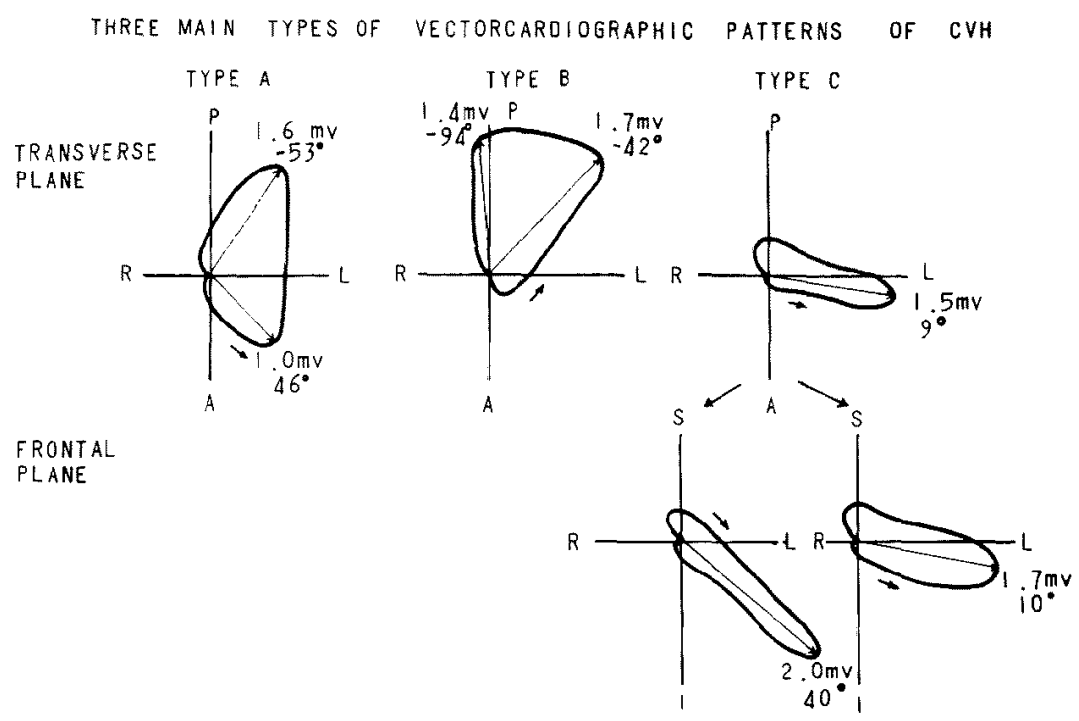

Fig. 5. The diagrammatic representation of the 3 main types of vectorcardiogram representing GVH.

Toyama and associates reported higher incidence of vectorcardiographic recognition of $\mathrm{CVH}$ in the adults with valvular diseases by using both the $\mathrm{QRS}$ and $\mathrm{T}$ loops. Combined ventricular hypertrophy was considered present if the transverse QRS loop is directed to the left and posteriorly to suggest LVH and the transverse $T$ loop is displaced to the left and posteriorly to suggest RVH. ${ }^{16)}$ However, this criteria including the direction of the maximum $T$ vector are not applicable in the patients who have been receiving digitalis and moreover such a posteriorly displaced $\mathrm{T}$ loop also may be observed in anterior myocardial ischemia. Actually, there were no specific changes in the Tloop in the present series, to aid in the diagnosis of $\mathrm{CVH}$ and most of the patients were receiving digitalis.

Gamboa, Klingemann, and Pipberger reported ${ }^{17}$ that the use of multivariate analysis of the orthogonal vectorial parameters by electronic computer led up to $69 \%$ of the diagnosis of CVH although claiming high false positives and false negatives. The percentage of recognition was the highest reported in the literature. However, such statistical approach in the diagnosis of CVH is not available for general clinical application.

Kováts-Hopff and Wyss postulated that if the initial left anterior forces of the QRS loop indicating LVH and the increased terminal right posterior forces or area indicating RVH were present simultaneously the diagnosis of CVH could be made. ${ }^{18)}$ They stated that if the direction of the initial 0.01 sec vector of the transverse QRS loop is less than $80^{\circ} \mathrm{LVH}$ could be considered 
present. Their results were in disagreement with our observation. Most of the GVH cases in the present series revealed fairly large initial forces directing leftward and anteriorly which could be attributed to right ventricular hypertrophy.

Our study revealed that in approximately $75 \%$ of the cases the vectorcardiograms showed signs of LVH or RVH alone. In the group with nonspecific QRS loop changes, several vectorcardiographic parameters, for example initial $0.02 \mathrm{sec}$ vector and terminal deflection, were outside normal range, otherwise the configuration of QRS loop was apparently normal.

\section{ACKNOWLEDGEMENTS}

'The author wishes to thank Drs. T. C. Chou and R. A. Helm for their critical review of the manuscript.

\section{REFERENCES}

1. Langendorf R, Hurvitz M, Katz L: Electrocardiographic patterns of combined ventricular strain. Brit Heart J 5: 27, 1943

2. Katz L, Wachtel H: The diphasic QRS type of electrocardiogram in congenital heart disease. Am Heart J 13: 302, 1937

3. Rosenman RH, Krause S, Hwang W: The electrocardiographic diagnosis of combined left and right ventricular hypertrophy. Am J Cardiol 4: 294, 1959

4. Pagnoni A, Goodwin J: The electrocardiographic diagnosis of combined ventricular hypertrophy. Brit Heart J 14: 451, 1952

5. Lipsett $M$, Zinn W: Anatomic and electrocardiographic correlation in combined ventricular hypertrophy. Am Heart J 45: 86, 1953

6. Scott RC: The correlation between the electrocardiographic patterns of ventricular hypertrophy and the anatomic findings. Circulation 21:256, 1960

7. Beregovich J, Bleifer S, Donoso E, Grishman A: The vectorcardiogram and electrocardiogram in ventricular septal defect with special reference to the diagnosis of combined ventricular hypertrophy. Brit Heart J 22: 205, 1960

8. Dack $\mathrm{S}$ : The electrocardiogram and vectorcardiogram in ventricular septal defect. Am $J$ Cardiol 5: 199, 1960

9. Papadopoulos C, Lee YC, Scherlis L: Isolated ventricular septal defect. Electrocardiographic, vectorcardiographic and catheterization data. Am J Cardiol 16: 359, 1965

10. Elliott LP, Taylor J, Schiebler CL: Combined ventricular hypertrophy in infancy. Vectorcardiographic observations with special reference to the $\mathrm{Katz}-\mathrm{Wach}$ tel phenomenon. Am J Cardiol 11: 164,1963

11. Grant RP: Clinical electrocardiography. The spatial vector approach. McGraw-Hill, New York, 77, 1957

12. Abbott-Smith CW, Chou TG: Vectorcardiographic criteria for the diagnosis of left ventricular hypertrophy. Am Heart J 79: 361, 1970

13. Varriale P, Kennedy RJ, Alfenito JC: Vectorcardiogram of combined ventricular hypertrophy. Posterior counterclockwise loop. Brit Heart J 31: 457, 1969

14. Bove KE, Scott RG: The anatomy of chronic cor pulmonale secondary to intrinsic lung disease. Prog Cardiovasc Dis 9: 227, 1966 
15. Chou TC, Helm RA: Clinical vectorcardiography. Grune and Stratton, New York and London, 98, 1967

16. Toyama S, Suzuki K: Vectorcardiogram in biventricular hypertrophy with the Frank system. Jap Circulat J 34:549, 1970

17. Gamboa R, Klingemann JD, Pipberger HV: Computer diagnosis of biventricular hypertrophy from the orthogonal electrocardiogram. Girculation 39: 72, 1969

18. Kovats-Hopff L, Wyss OA: Vectorcardiographic signs of biventricular hypertrophy. Cardiologia 48: 269, 1966 